\title{
A norma de responsabilidade social e a discriminação da mulher negra no setor industrial
}

\author{
Valdenice Portela Silva ${ }^{\mathrm{I}, 1}$, Marcus Eugênio Oliveira Lima ${ }^{\mathrm{I}, 2}$ e Patrícia da Silva ${ }^{\mathrm{II}, 3}$ \\ ${ }^{1}$ Universidade Federal de Sergipe (São Cristóvão, Sergipe, Brasil) \\ ${ }^{\text {II }}$ Universidade Federal do Acre (Rio Branco, Acre, Brasil)
}

\begin{abstract}
O objetivo deste estudo foi analisar, de forma comparativa, os impactos da norma de responsabilidade social empresarial e a discriminação das mulheres negras, na indústria de transformação sergipana. Para tanto, foram utilizados os microdados da Relação Anual de Informações Sociais (RAIS) do Ministério do Trabalho e Emprego (MET) de 2007/2008 e 2013/2014. A partir da análise dos dados, nota-se, em relação à discriminação de gênero, uma tendência à predominância masculina no setor da indústria de transformação sergipana. Os dados indicam também que não apenas o sexo feminino é aquele com menor presença no setor industrial, mas é a mulher de cor preta que possui os menores percentuais de inclusão no setor industrial sergipano. Esse cenário comparativo de discriminação de gênero e raça pouco se alterou com a introdução da norma de responsabilidade social empresarial, a partir da década de 1990. Os resultados são discutidos de acordo com as teorias do sexismo e do racismo.
\end{abstract}

Palavras-chave: Indústria, Raça, Gênero, Norma social, Discriminação.

Social responsibility standard and the discrimination of black women in the industrial sector

The aim of this study was to analyses comparatively the impact of social responsibility norm on black women discrimination in Sergipe's manufacturing industry, between 2007 and 2008 vs. 2013 and 2014. The data was collected from the Annual Report of Social Information (RAIS) of Ministry of Labor and Employment (MET). The results show a strong pattern of gender discrimination, indicating a male predominance in the Sergipe's manufacturing industry. The data also shows race discrimination, once the blacks were sub represented. Most important, was the intersection between gender and race, which demonstrates that black women had the lowest indexes of inclusion and salary in the industrial sector. This scenario of gender $\mathrm{x}$ race discrimination has changed little from 2007/08 to 2013/14, with the introduction of the social responsibility norm since the 1990s. The results were discussed in accordance to theories of sexism and racism.

Keywords: Industry, Race, Gender, Social norm, Discrimination.

\footnotetext{
${ }^{1}$ https://orcid.org/0000-0002-8812-6884

${ }^{2}$ https://orcid.org/0000-0001-5280-130X

${ }^{3}$ https://orcid.org/0000-0003-3435-7852
} 


\section{Introdução}

elevada desigualdade entre homens e mulheres, negros e brancos é uma característica
marcante no mercado de trabalho brasileiro. Segundo dados da Pesquisa Nacional por Amostra de Domicílios (PNAD), do período de 1995 a 2009, verifica-se que 42,7\% dos homens brancos e 35,4\% das mulheres brancas têm emprego com carteira assinada e, no polo oposto, $36,9 \%$ dos homens negros e $24,8 \%$ das mulheres negras (pardas e pretas). De modo que, mesmo com o aumento do grau de instrução das mulheres, no respectivo período, ainda é o segmento masculino aquele com maior acesso ao emprego estável e de maior proteção social, em comparação ao segmento feminino (Lima, Rios, \& França, 2013).

Em 2007 e 2010, considerando as 500 maiores empresas do Brasil, foi constatado que o empregado em pior situação era a mulher negra devido à sub-representação de $9,3 \%$, no quadro funcional; 5,6\%, na supervisão, e 0,5\%, no quadro executivo. Essas estatísticas significam a presença de seis negras (todas pardas) entre as 119 mulheres ou os 1.162 diretores, negros e não negros, de ambos os sexos, cuja cor ou raça tenha sido informada durante a pesquisa (Custódio \& Moya, 2007; Instituto Ethos, 2010) ${ }^{4}$.

Entre os anos de 2001 e 2011, foi observado que o grupo de mulheres que estava trabalhando, em 2001, representou 38\%, aumentando para 42\%, em 2011, o que denota a crescente entrada de mulheres no mercado de trabalho brasileiro. Esse resultado, em diferentes proporções, vale também para todas as regiões, exceto o Norte, onde a proporção de mulheres caiu no mesmo período de $37 \%$ para 36\%. Apesar da expressiva entrada das mulheres no mercado de trabalho, a diferença de rendimentos entre homens e mulheres permanece relevante, mesmo dentre os que desempenham funções produtivas semelhantes. Tanto que, no período analisado, a diferença salarial das mulheres em relação aos homens foi de $20 \%$ para o Brasil, o mesmo para a região Centro Oeste, 22\% para a região Nordeste, $27 \%$ para o Norte e 15\% para as regiões Sul e Sudeste (Souza, Salvato, \& França, 2013).

De modo geral, observam-se os seguintes resultados, a partir dos dados apresentados pela maioria dos estudos sobre a discriminação no mercado de trabalho: a) uma predominância de homens no mercado de trabalho em relação às mulheres; b) um aumento na participação das mulheres no mercado de trabalho, em especial, das mulheres negras; c) as mulheres ganham menos do que os homens, e os negros menos do que os brancos. Os maiores salários são dos homens brancos e os menores salários das mulheres pretas (Soares, 2000).

Os dados mostram que, passados mais de 60 anos de lutas pelos direitos civis e promulgação de normas contra o preconceito, como a Convenção Internacional Sobre a Eliminação de Todas as Formas de Discriminação Racial (ONU), de 1965, ainda há diferenças no mercado de trabalho entre homens e mulheres brancos e negros. Uma das explicações para essa diferença repousa no preconceito e no racismo, incluindo as novas formas de expressão e também as mais tradicionais - preconceito e racismo - que se apresentam como um contraponto às tradicionais ou clássicas (Lima \& Vala, 2004). No Brasil, onde até pouco tempo

\footnotetext{
${ }^{4}$ O Instituto Ethos é uma OSCIP, cuja missão é mobilizar, sensibilizar e ajudar as empresas a gerir seus negócios de forma socialmente responsável, tornando-as parceiras na construção de uma sociedade justa e sustentável (Instituto Ethos, n. d.).
} 
atrás não existia reconhecimento oficial do racismo, essas novas manifestações, assim como as expressões mais fora de moda, têm a marca da discriminação, ou seja, da restrição dos espaços e dos acessos a indivíduos e grupos minoritários, em relações intergrupais, como é o caso das relações de trabalho. No contexto de análise da discriminação no trabalho, merece destaque o racismo aversivo que, diferentemente do tradicional (cujas expressões preconceituosas são explícitas), opera de forma sutil e quase imperceptível (Silva, Lima, \& Silva, 2017).

Dentro desse contexto, este estudo tem o objetivo de analisar a discriminação de mulheres negras (pretas e pardas) na indústria de transformação sergipana, após a norma de responsabilidade social empresarial se consolidar, na década de 1990, com maior força no cenário nacional e internacional. O corpus da pesquisa foi fornecido pela base de dados Relação Anual de Informações Sociais (RAIS) do Ministério do Trabalho e Emprego (MTE). Para análise do efeito da norma, foram considerados, de forma comparativa, os anos de 2007, 2008, 2013 e 2014.

\section{Racismo e relações sociais}

A fim de apresentar um panorama de como as relações étnico-raciais foram investigadas pela pesquisa em Psicologia no Brasil, na primeira década do século XXI, Martins, Santos e Colosso (2013) realizaram uma revisão sistemática nas bases de dados Scientific Eletronic Library Online (SciELO) e Literatura Latino-Americana e do Caribe em Ciências da Saúde (LILACS). Nessa pesquisa, foram encontrados 41 artigos, entre o período de 2000-2009, e distribuídos nas seguintes categorias relacionadas ao conteúdo dos trabalhos: "Novas formas de compreensão do preconceito", "Racismo: história e ideologia", "Identidade étnico-racial e manifestações culturais" e "Recepção das ações de promoção da igualdade étnico-racial pela sociedade brasileira".

Nos estudos analisados, foi observado que os procedimentos utilizados para coleta de dados foram pesquisas de campo com o predomínio da entrevista e procedimentos experimentais. Os 41 artigos, objetos de estudo da revisão sistemática, indicam que o tema das relações étnico-raciais tem sido objeto de investigação da Psicologia, notadamente da Psicologia Social. Em alguns desses estudos, existe a preocupação de investigar as formas sutis de manifestação de atitudes preconceituosas, as quais, na atualidade, adquirem formas disfarçadas e indiretas com o objetivo de não ferir a norma de igualdade nem ameaçar a autoimagem de pessoa igualitária (Martins et al., 2013).

Numa outra revisão sistemática sobre os estudos com foco no preconceito racial, cujas buscas ocorreram nas bases de dados Periódicos Eletrônicos de Psicologia (PePSIC), Index Psi Periódicos, PsycINFO, SciELO e LILAC, utilizando os termos "racismo" ou "preconceito racial", foram encontrados 77 artigos publicados desde 2001. Os temas mais frequentes utilizados estavam relacionados às cotas de acesso ao Ensino Superior; nos artigos empíricos, às origens do preconceito racial e suas formas de expressão, às consequências do preconceito para as vítimas racismo e às influências de teorias raciais no desenvolvimento da Psicologia. Entre as lacunas identificadas, estão escassas pesquisas que tenham usado, como cerne, adultos não universitários e pessoas que pertençam a grupos discriminados (Sacco, Couto, \& Koller, 2016). 
Ao considerar a relevância social do estudo sobre preconceito racial no Brasil e as contribuições que a Psicologia pode gerar, a quantidade de artigos sobre o tema no país ainda é restrita (Sacco, Couto, \& Koller, 2016), isso porque, dos 279 artigos não duplicados, encontrados inicialmente, apenas 66 eram realmente da Psicologia e tratavam do preconceito racial.

Quanto à discriminação, um dos estudos, que articula raça e gênero, tem como foco o mercado de trabalho e base teórica na Psicologia Social é "Mulher negra no mercado de trabalho", de Maria Aparecida Silva Bento, publicado em 1995. Bento (1995) analisa os mecanismos da discriminação racial, no trabalho, utilizando os depoimentos de trabalhadores/as negros/as. Não diferentemente de boa parte das pesquisas sobre preconceito e discriminação, no campo da Psicologia, a pesquisa de Bento (1995) também faz uso de entrevistas para identificar atitudes discriminatórias consideradas explícitas e analisa as percepções e significados da discriminação.

Com efeito, nos estudos sobre racismo, preconceito e discriminação, que utilizam como base teórica a Psicologia Social, normalmente, é identificado o uso de métodos como os estudos de percepção, sondagens de atitudes e experimentos de laboratório e de campo para mensurar a discriminação (são as medidas explícitas). Por enquanto, são exíguas as investigações que analisam as práticas ou resultados sociais, a exemplo da discriminação no mercado de trabalho, adotando bancos de dados de grande escala, que investigam desigualdades nos resultados sociais entre grupos (medidas implícitas) (Pager, 2006; Quillian, 2006).

A partir do surgimento de novas expressões de preconceito, em esferas sociais como a do trabalho, aparecem novas formas de discriminar, quase imperceptíveis, as quais, na maioria das vezes, exigem novos procedimentos para identificá-las. Além das atitudes mais evidentes ou explícitas, há também a sobreposição de categorias que levariam, não apenas à discriminação interseccional, mas também à manifestação de atitudes preconceituosas de forma mais automática ou inconsciente no ambiente de trabalho.

Nesse sentido, a questão que se coloca é a de saber como mensurar a discriminação racial diante das mudanças de atitudes raciais após a Segunda Guerra Mundial e os movimentos sociais no mundo como um todo, a exemplo dos movimentos pelos direitos civis nos EUA, quando as pessoas, em determinados ambientes (como na esfera do trabalho), se tornaram menos dispostas a expressar abertamente seus sentimentos e crenças preconceituosas (Dovídio \& Gaertner, 2004; Lima \& Vala, 2004).

O uso de atributos produtivos ou não produtivos, para mensurar a discriminação, tem sido feito nos estudos econômicos sobre discriminação no mercado de trabalho, entre eles os da Teoria Neoclássica da Discriminação (TND), da Teoria Estatística da Discriminação e da Teoria da Segmentação do Mercado de Trabalho (Silva, Lima, \& Silva, 2017). Na maioria desses estudos, a análise da discriminação parte da remuneração média recebida por homens e mulheres negros e brancos, justamente para verificar a desigualdade existente no mercado de trabalho. Acredita-se que se os trabalhadores, com os mesmos atributos profissionais, mesma escolaridade, mas de raça ou gênero distintos, recebem salários diferentes é porque há discriminação de raça e gênero.

É interessante observar que, embora muitos dos estudos sobre discriminação no mercado de trabalho estejam mais preocupados com os motivos que levam à discriminação do 
que com os mecanismos da discriminação, há pesquisas que apontam a relação entre a discriminação e fatores psicossociais. Carneiro, Heckman e Masterov (2004), ao analisarem a relação entre as ações afirmativas e as diferenças salarias no mercado de trabalho de homens e mulheres afro-americanos e hispânicos, nos Estados Unidos, estimaram que as diferenças na escolaridade, entre hispânicos e afro-americanos, acabam influenciando as diferenças salariais no mercado de trabalho. Em função das expectativas negativas que a discriminação gera nos pais das crianças negras, estes podem não incentivar seus filhos nos estudos, comprometendo não apenas o desempenho escolar dos filhos, mas o seu futuro profissional.

Em contrapartida, Cruz (2010) pondera que os estudos econométricos sobre a discriminação no mercado de trabalho não abarcam todos os aspectos da discriminação, isso porque certos trabalhadores exigem uma análise que vai além da Teoria da Discriminação Econômica (TDE). Para o autor, a discriminação no mercado de trabalho não advém apenas dos empregadores, mas também de fatores psicossociais como as crenças e os sentimentos dos discriminados, os quais, por se sentirem incapazes de assumir certos cargos, nem sequer cogitam a possibilidade de trabalharem em determinados lugares ou assumirem certos postos de trabalho.

Analisando a mobilidade social de mulheres negras na estrutura social brasileira, ainda que tenha ocorrido uma elevação no nível de escolaridade da mulher negra no Brasil, nos últimos 10 anos, ela continua a ocupar os mais baixos níveis sociais. Enquanto homens brancos se encontram nas melhores ocupações profissionais, as mulheres negras são as que enfrentam fortes barreiras para converterem suas melhores qualificações em maiores vantagens no mercado de trabalho, isso porque frequentam os cursos de formação menos valorizados pelo mercado de trabalho brasileiro (Carvalhaes \& Rodrigues, 2019; Lima, Rios, \& França, 2013).

O conceito de discriminação adotado neste artigo consiste no ato de classificar o outro, "baseado em categorias naturais e sociais sem que haja relação com as capacidades e os méritos individuais, ou com o real comportamento da pessoa. É o ato de separar que tanto pode privilegiar uma pessoa ou grupo como prejudicá-la/o" (Ministério da Educação, n. d., p. 2) e exige uma compreensão acerca do tipo de diferenciação que produz e a espécie de informação que sustenta e gera exclusão. Os mecanismos discriminatórios são entendidos a partir do momento em que são feitas tais diferenciações, pois elas se configuram de distintas maneiras em cada sociedade. Em termos psicossociais, a discriminação acontece quando o tratamento desigual for injustificável socialmente (Mummendey \& Wenzel, 1999).

Entende-se a desigualdade como o oposto da igualdade, a qual está atrelada à discussão dos direitos à diferença. As sociedades democráticas estão constituídas de grupos minoritários que reclamam para si uma nova forma de discriminação, dita positiva, por meio da qual esses grupos teriam igualdade de oportunidade pela equidade com respeito às diferenças. Deste modo, a ideia de desigualdade estaria associada à de diferença; ou seja, à ideia de pessoa ou unidade absolutamente singular e, por sua vez, à de igualdade de oportunidades que contribui para o surgimento de políticas de justiça social, em detrimento das liberdades individuais ou da promoção do nivelamento das necessidades humanas (Carone, 2009).

A discriminação no mercado de trabalho compreende a exclusão social (ou inclusão precarizada) na esfera do trabalho de certos indivíduos em razão de atributos relativos à produtividade e eficiência (escolaridade, experiência profissional, região de moradia e faixa etária) e outros não relativos (raça e gênero). Pode ser classificada em: a) discriminação 
salarial; b) discriminação de emprego; c) discriminação de trabalho e ocupação; e d) discriminação de acesso ao capital humano (Cruz, 2010).

O mercado de trabalho é, portanto, um importante contexto de análise da discriminação de raça e gênero, sendo possível mensurar a discriminação por meio da análise estatística de banco de dados de grande escala que investiga desigualdades nos resultados sociais entre grupos.

\section{Método}

A abordagem desta pesquisa apresenta características quantitativas com procedimentos da pesquisa documental que se divide em dois momentos: a análise preliminar do documento e a análise descritiva. A análise preliminar abrange as seguintes etapas: a identificação dos autores do documento, a identificação da natureza do texto, o exame do contexto da produção do documento, a verificação de sua autenticidade e a confiabilidade da informação transmitida (Vasconcellos \& Silva, 2013). A análise descritiva foi conduzida para conhecer o perfil sociodemográfico da população estudada (sexo, cor ou raça, escolaridade e renda mensal) e avaliar a relação entre a participação da mulher negra na indústria de transformação sergipana e a norma de responsabilidade social empresarial.

Segundo a Federação da Indústria do Estado de Sergipe (2012) e o Ministério do Trabalho e Emprego (2014), a população da indústria de transformação em Sergipe está estimada em 758 empresas e 48.306 trabalhadores, dentre os quais 23\% são da cor branca, $8 \%$ da cor preta e $59 \%$ da cor parda. Fizeram parte da pesquisa 149.635 vínculos formais dos trabalhadores da indústria de transformação sergipana, cadastrados pela Relação Anual de Informações Sociais (RAIS) do Ministério do Trabalho e Emprego (MTE), nos anos de 2007, 2008, 2013 e 2014.

A indústria de transformação sergipana, pela Classificação Nacional de Atividades Econômicas (CNAE), utilizada em cadastros e registros de pessoa jurídica, é composta dos seguintes subsetores: Extrativa Mineral; Produção Mineral Não Metálico; Indústria Metalúrgica; Indústria Mecânica; Elétrico e Comunicação; Material de Transporte; Madeira e Mobiliário; Papel e Gráfica; Borracha, Fumo, Couros; Indústria Química; Indústria Têxtil; Indústria de Calçados; Alimentos e Bebidas; Serviço Utilidade Pública e Construção Civil (Instituto Brasileiro de Geografia e Estatística, 2007).

É importante salientar que o registro administrativo RAIS contabiliza vínculos existentes e não o número de indivíduos, isso porque um assalariado pode ter mais de um vínculo. Neste caso, os empregos são sinônimos de vínculos empregatícios, não são postos de trabalho ou indivíduos. O universo representado pela RAIS está restrito ao segmento formal do mercado de trabalho e consiste na contabilização da soma dos empregos assalariados regulados pela Consolidação da Legislação Trabalhista (CLT) e pelos estatutários (Ministério do Trabalho e Emprego, 2008; Servo, Furtado, Amorim, Ribeiro, \& Souza, 2006).

Estudos têm demonstrado que, embora seja uma fonte de dados relativamente recente (criada em 1975), a RAIS se constitui como um excelente instrumento de análise de curto e longo prazo do mercado de trabalho brasileiro (Saboia \& Tolipan, 1985). Ela é confiável para a 
análise do mercado de emprego formal (Negri, Castro, Souza, \& Arbache, 2001), embora possa, no que concerne ao quesito raça ou cor, apresentar alguma vulnerabilidade, levando a um perfil de distribuição relativamente mais branco do que os Microdados PNAD do IBGE (Paixão, Rosseto, \& Monçores, 2013).

O motivo para escolha dos anos 2007, 2008, 2013 e 2014 diz respeito às diversas práticas empresariais ocorridas antes e após o respectivo período pesquisado; entre elas, a criação, em 1998, do Instituto Ethos e com ela a elaboração de documentos como: O compromisso das empresas com a valorização da mulher, de 2004 e O compromisso das empresas com a promoção da igualdade racial, de 2006. A intenção é comparar os anos de 2007 e 2008 com os de 2013 e 2014, numa abordagem longitudinal em relação ao período de consolidação da norma de responsabilidade social empresarial no contexto organizacional brasileiro. Outra razão para escolha desse período refere-se ao fato de que o quesito raça ou cor, introduzido em 1998, no questionário RAIS, somente passou a ser disponibilizado online pela Coordenação Geral de Estatística e Trabalho (CGET) do TEM, a partir de 2006.

\section{Resultados e discussão}

Com o objetivo de analisar o impacto da norma de responsabilidade social empresarial sobre a participação de mulheres negras (pretas e pardas) na indústria de transformação sergipana, por meio da base de dados RAIS, nos anos de 2007, 2008, 2013 e 2014, as variáveis analisadas são os atributos produtivos e não produtivos relacionados à discriminação no mercado de trabalho, entre eles: escolaridade, rendimentos, ocupação profissional, raça e sexo. Por meio das respectivas variáveis, foi investigada a relação existente entre as desigualdades de gênero e raça e a norma de responsabilidade social empresarial com a observação da evolução das desigualdades no mercado de trabalho. Utilizaram-se, como parâmetro de comparação, os dados dos Censos Demográficos de 2000 e 2010. Assim, os primeiros dados apresentados são pertencentes às desigualdades de gênero, em seguida às desigualdades de raça e ao cruzamento entre as categorias raça ou cor e sexo, que permitiu identificar o nível de exclusão que a mulher negra, em relação aos demais grupos, está sujeita, na indústria de transformação sergipana.

\section{Desigualdades de gênero}

Quanto às desigualdades de gênero, observa-se, na Figura 1, a predominância e a constância da inserção masculina no setor da indústria de transformação sergipana, representando $73 \%$ dos vínculos formais dos trabalhadores e $27 \%$ das trabalhadoras, nos anos de 2007 e 2008. Nos anos de 2013 e 2014, a taxa de sobrerrepresentação masculina praticamente não se altera, diminuindo apenas $1 \%$. 
Figura 1: População ocupada com carteira assinada, segundo participação dos grupos por sexo, distribuída na indústria de transformação sergipana em 2007, 2008, 2013 e 2014

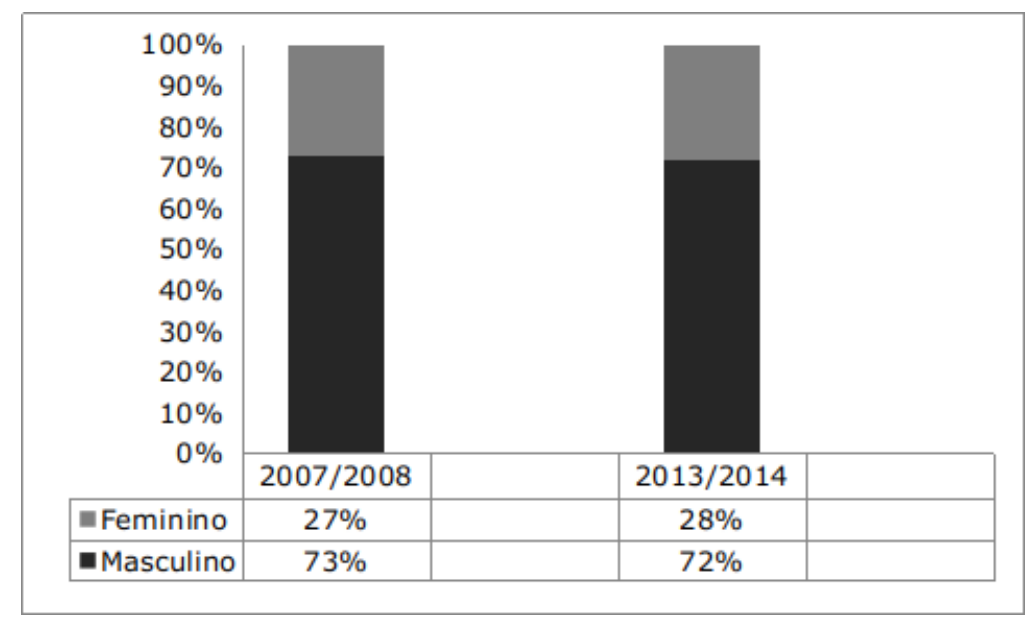

Fonte: Elaboração própria.

Em relação à população ocupada com carteira assinada, no censo demográfico de 2000, verifica-se a predominância masculina de $63 \%$ para os homens e $37 \%$ para as mulheres (Instituto Brasileiro de Geografia e Estatística, 2000). Em 2010, essa desproporção representacional se inverteu a favor das mulheres. Isto é, os valores foram para $48 \%$ e 52\%, uma redução percentual de $15 \%$ da participação masculina no mercado de trabalho sergipano mais um aumento de $15 \%$ da presença feminina em diversos setores da economia sergipana.

Cabe ainda referir que, do total de 2.037 .047 da população residente em Sergipe, segundo o Censo de 2010, 49\% e 51\% representam respectivamente a população masculina e feminina. Destes, 2,3\%, nos anos de 2007 e 2008, e 3,05\%, nos anos de 2013 e 2014, retratam os vínculos formais dos homens da indústria de transformação sergipana.

Quanto aos vínculos formais das mulheres na indústria, referentes aos dados RAIS, estes correspondem a 0,83\% e 1,2 \% do total de 2.037 .047 da população residente, sergipana, do Censo de 2010, nos períodos de 2007 e 2008, 2013 e 2014. Isso significa que uma pequena quantidade da população feminina, residente, sergipana se encontrava empregada no setor industrial sergipano e em situação regular no mercado de trabalho.

No Censo Demográfico de 2010 (Instituto Brasileiro de Geografia e Estatística, 2014), a maior diferença entre os sexos se encontra na Educação Superior e Ensino Médio completo, cuja proporção dos que completaram a graduação é de $25 \%$ para as mulheres e $9,9 \%$ para os homens. Em se tratando da distribuição percentual da população sem instrução, por todo Brasil, 47,8\% corresponde ao sexo feminino e 50,8\% ao masculino na categoria sem instrução, confirmando-se, então, uma evolução no nível de instrução do sexo feminino em relação ao masculino.

Apesar de o aumento no nível de instrução das mulheres e da escolaridade significar um valor que eleva a produtividade da economia como um todo, capaz de gerar efeitos virtuosos como a melhora do salário, as mulheres permanecem recebendo menores salários em relação aos homens no Brasil, independentemente da área de formação profissional (Instituto Patrícia Galvão, 2014). 
No que tange às desigualdades de gênero, cabe destacar uma contínua supremacia dos vínculos formais masculinos, no setor da indústria de transformação sergipana. Isso porque a mão de obra feminina não só continua a ser minoria no setor industrial sergipano, como também a receber os menores salários, a possuir os mais baixos níveis de instrução e se encontra menos presente nos cargos de direção. Por isso, a avaliação empreendida autoriza afirmar que o ingresso feminino no mundo laboral apenas tem a aparência de conquista.

Com a identificação de uma pequena participação feminina na indústria de transformação sergipana, parece ter ocorrido uma alteração na forma do patriarcado essencialmente privado "para o patriarcado público, com a expressão nas relações de segregação e subordinação existentes nas estruturas e no funcionamento das instituições públicas" (Casaca, 2009, p. 30). É como se houvesse, segundo a teoria do patriarcado, um acordo implícito entre homens e mulheres acerca de suas responsabilidades. À mulher é atribuído o trabalho doméstico, pelo qual não é remunerada, ao homem à atividade econômica, pela qual é remunerado, excluindo, dessa forma, as mulheres da esfera laboral e das profissões mais bem remuneradas, qualificadas e prestigiadas.

A partir do determinismo biológico (a dicotomia fêmea e macho), é possível entender como se reproduzem as diferenças entre homens e mulheres, no mercado de trabalho, via a determinação de papéis sociais; ou seja, o papel que deve ser exercido pela mulher, já que, ao ser vista historicamente como a cuidadora do lar por conta dos estereótipos que lhe são atribuídos (de ser culturalmente concebida como sensível, fraca, desprotegida etc.), a ela foram outorgados cargos ou atividades no mercado de trabalho, nos quais fosse capaz de pôr em prática o que lhe foi socialmente imputado pelo sexo.

Figura 2: População ocupada com carteira assinada, segundo participação dos grupos por sexo, distribuída por remuneração média na indústria de transformação sergipana em 2007, 2008, 2013 e 2014

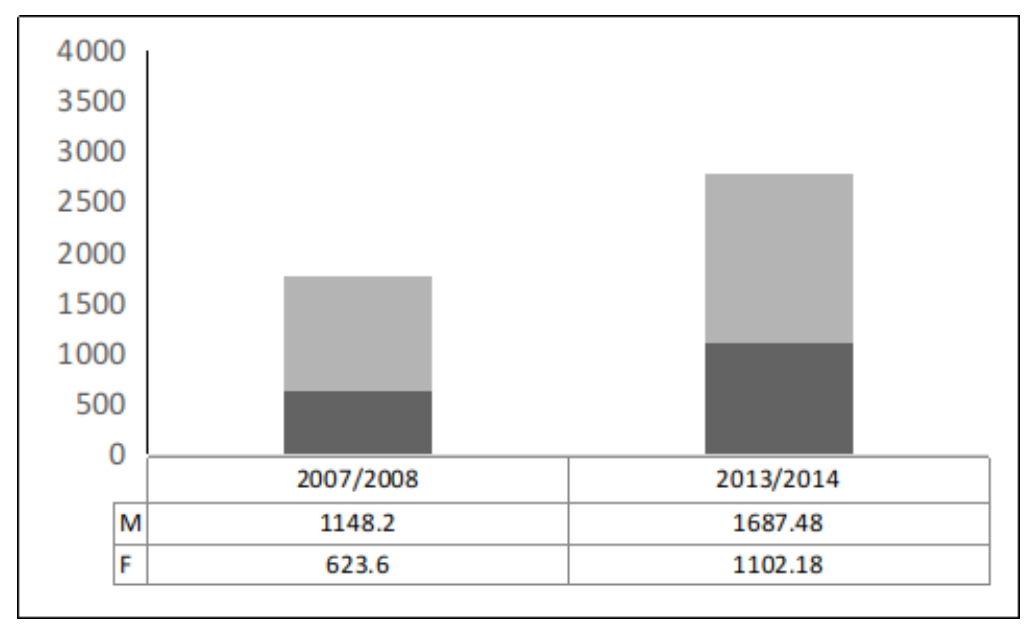

Fonte: Elaboração própria.

A discriminação salarial é uma das formas de exclusão no mercado de trabalho, ela consiste na diferença salarial não justificável entre categorias sociais. Na Figura 2, observa-se que houve um aumento considerável na remuneração média dos trabalhadores, nos anos de 2007, 2008, 2013 e 2014, com um crescimento de mais de 32\%. Todavia, a remuneração das trabalhadoras é substancialmente mais baixa que a dos trabalhadores. Em 2007 e 2008, a renda 
das mulheres equivalia a 54,3\% da renda dos homens, já em 2013 e 2014 equivale a 65,3\%. A discriminação salarial se mostrou consistente e mesmo crescente, no período analisado, não obstante, o montante da remuneração dos trabalhadores ter aumentado de forma significativa.

Quando comparamos esses dados com os dados gerais de remuneração da população brasileira com mais de 10 anos de idade, segundo o IBGE (Instituto Brasileiro de Geografia e Estatística, 2014), vemos que o rendimento médio mensal das mulheres correspondia a $65 \%$ do auferido pelos homens, no ano de 2000, e subiu, em 2010, para 68\%. Não é, contudo, um crescimento linear. $\mathrm{Na}$ região Nordeste, a renda das mulheres que equivalia a $72 \%$ da masculina, em 2000, caiu para 68\%, dez anos depois. Se considerarmos apenas os dados da população ocupada, notamos que, em 2013, as mulheres recebiam, no Brasil, 79,5\% do salário dos homens e 80\% em 2014. Uma ampla pesquisa da CATHO, em 2017 (Kometani, 2017), feita com 13.161 profissionais, avaliou oito funções, de estagiários a gerentes, e constatou que as empresas pagam menos às mulheres em todos os cargos e, sobretudo, nos mais especializados.

Nesse sentido, o sexismo institucional compreende a exclusão promovida por entidades, organizações e comunidades que impõem às mulheres certas barreiras, impedindolhes de ter as mesmas oportunidades dos homens em situação de trabalho, já que são elas a receberem os menores salários, mesmo assumindo cargos semelhantes aos dos homens, e a serem excluídas de certas posições atribuídas ao sexo masculino.

Por outro lado, além de fatores psicossociais ligados ao efeito dos estereótipos sobre os julgamentos sociais dos responsáveis pelo recrutamento e seleção de pessoal do setor industrial, há o fato de que as diferenças salariais tanto podem estar associadas à produtividade (Teoria Estatística de Discriminação) quanto à qualificação da mão de obra (Teoria do Capital Humano) e à localização geográfica do produto (Teoria da Segmentação do Mercado de Trabalho).

No entanto, como a qualificação da mão de obra feminina e sua capacidade produtiva vêm aumentando nos últimos anos, acredita-se que, além dos atributos "produtivos", há os "não produtivos" (raça ou cor e sexo) que podem contribuir para atual posição das operárias do setor industrial sergipano. Fora o efeito do sexo a determinar as diferenças entre homens e mulheres na esfera do trabalho, há também a categoria raça ou cor que pode acarretar desigualdades raciais no mercado de trabalho sergipano.

\section{Desigualdades de raça}

Em relação às desigualdades de raça, presentes no setor industrial sergipano, a Figura 3 mostra uma tendência à concentração maior de trabalhadores pardos, representando 66\%; outros 27\% brancos e 7\% pretos, em 2007 e 2008. Da mesma forma, em 2013 e 2014, mantêmse os $66 \%$ de trabalhadores pardos, $26 \%$ brancos e $8 \%$ pretos. Tais resultados sugerem que a predominância de pessoas pardas do setor industrial sergipano reflete a própria composição etnográfica do estado. 
Figura 3: População ocupada com carteira assinada, segundo participação dos grupos de raça ou cor, distribuída na indústria de transformação sergipana em 2007, 2008, 2013 e 2014

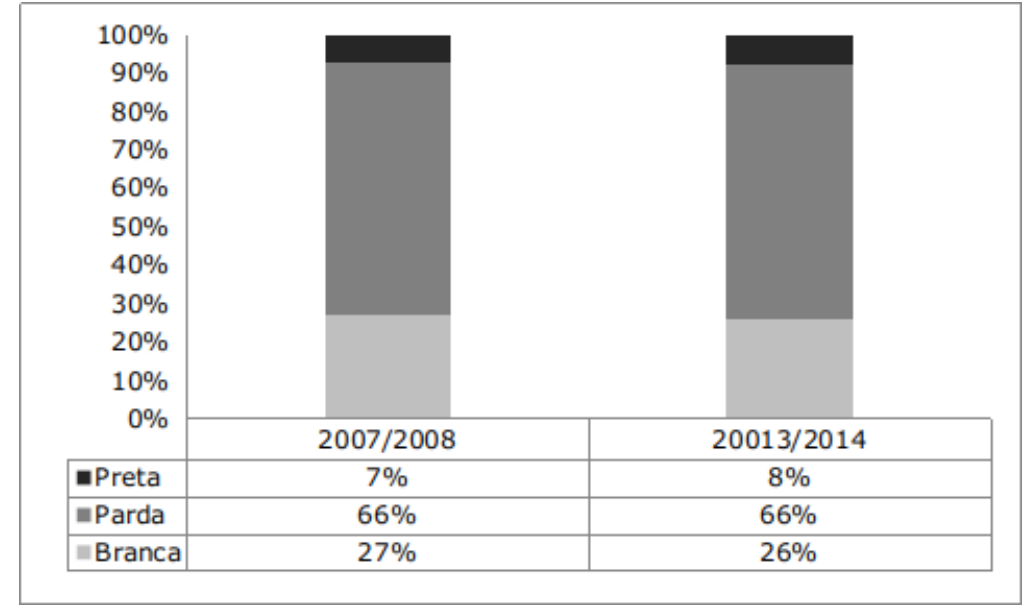

Fonte: Elaboração própria.

Como a ação afirmativa de incentivo à imigração não teve a mesma evidência em Sergipe, como no Oeste Paulista (Domingues, 2008), acredita-se que a tendência à predominância de pardos na indústria de transformação sergipana não se deu obrigatoriamente por conta do processo imigratório, da substituição da mão de obra ex-escrava pela imigrante, mas como consequência da mestiçagem da população nordestina, fomentada pela ideologia do branqueamento, que se constituiu como elemento central das relações sociais no Brasil (Telles, 2004).

Segundo Domingues (2008), o período de formação do trabalho livre em Sergipe não se deu da mesma forma que o Oeste Paulista, onde a imigração europeia foi um fator decisivo para o abastecimento de força de trabalho da grande lavoura; no entanto, houve diversas vias de transição para o trabalho livre no Brasil. Em Sergipe, onde se optou pela estratégia de persuadir ou obrigar a população livre a se engajar nos trabalhos agrícolas, crê-se que, supostamente, esse fato tenha contribuído para a grande presença de trabalhadores pardos na indústria de transformação sergipana após a revolução industrial.

De acordo com a literatura relacionada à discriminação no mercado de trabalho brasileiro, constatam-se, na Figura 4, que são os trabalhadores brancos aqueles com maiores rendimentos em relação aos pardos e pretos. $\mathrm{E}$ os trabalhadores pretos os que expõem remunerações substancialmente mais baixas que os demais segmentos apresentados pelos dados RAIS relacionados às desigualdades de raça.

Nesse sentido, mesmo que a mão de obra preta da indústria de transformação sergipana apresente as mais baixas taxas de participação, os mais baixos níveis de escolaridade e a menor remuneração média, no período analisado, ainda assim houve, no mesmo período, uma evolução na remuneração média tanto desses trabalhadores, bem como daqueles pertencentes ao grupo de cor parda. 
Figura 4: População ocupada com carteira assinada, segundo participação dos grupos de raça ou cor, distribuída por remuneração média na indústria de transformação sergipana em 2007, 2008, 2013 e 2014

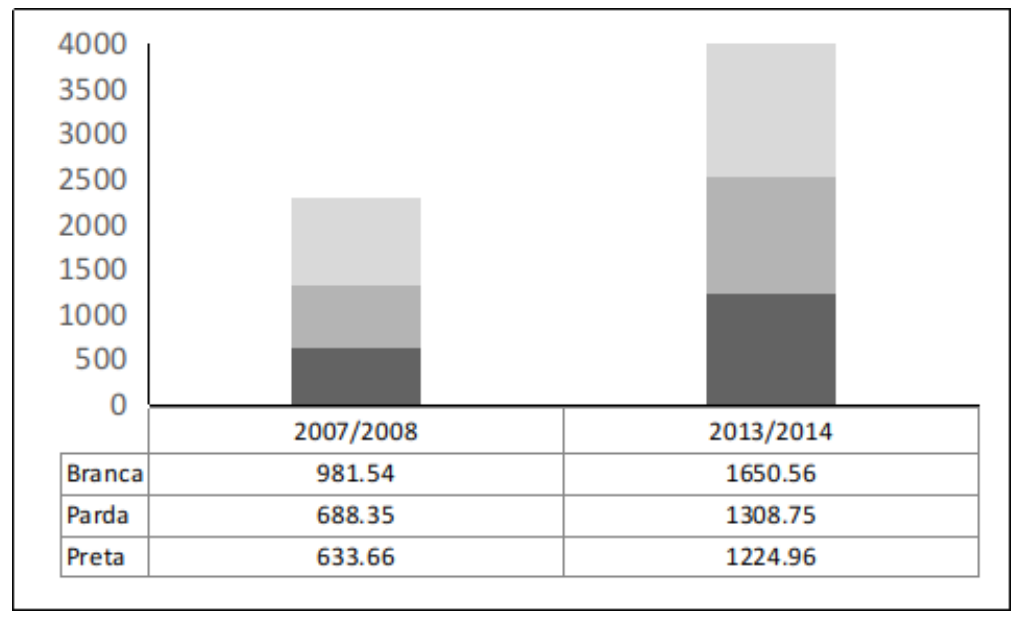

Fonte: Elaboração própria.

\section{Desigualdades de gênero e raça}

Articulando as categorias gênero e raça, o Quadro 1 mostra os vínculos formais de trabalhadores da cor parda com $48 \%$ do total dos vínculos formais da indústria de transformação sergipana no período analisado. O percentual de vínculos formais da mão de obra do sexo masculino da cor branca é de $19 \%$ e da preta de $6 \%$. Já o percentual de vínculos formais da mão de obra do sexo feminino constitui $19 \%$ de pardas, $8 \%$ de brancas e $2 \%$ de pretas. Chama a atenção também, na mesma estatística, uma tendência à predominância da mão de obra masculina parda nesse setor industrial e uma pequena participação da mão de obra feminina preta. Apesar disso, constata-se uma sutil evolução na taxa de participação das trabalhadoras negras no respectivo setor econômico, isso em relação à mão de obra preta.

Do total de 606.588 da população sergipana ocupada com carteira, no Censo de 2000 (Instituto Brasileiro de Geografia e Estatística, 2000), 59,3\% representam as trabalhadoras pardas e $62 \%$ os trabalhadores pardos. A mão de obra que exibe a menor taxa de participação (6,2\%) deste total é a de cor preta e sexo feminino. Já do total de 1.694 .022 da população ocupada com carteira, apresentado pelo Censo de 2010 (Instituto Brasileiro de Geografia e Estatística, 2010), 62\% correspondem à cor parda do sexo feminino e 62,4\% equivalem à cor parda do sexo masculino, o que significa existir uma predominância do sexo masculino no mercado de trabalho sergipano. A população ocupada com menor taxa de participação (9\%), no mesmo censo, é a de cor preta e sexo feminino. Apesar de a participação de mulheres pretas ainda ser pequena, houve um aumento percentual de 2,8\% entre os anos de 2000 e 2010.

A população residente sergipana branca, parda e preta, segundo o Censo de 2000, consiste respectivamente em 562.858, 1.850 .409 e 111.461. De acordo com os dados RAIS, nos anos de 2007 e 2008, esta população pode representar a indústria de transformação sergipana da seguinte forma: $2 \%$ (do sexo masculino) e 1\% (do sexo feminino) constituem os vínculos formais dos trabalhadores brancos, $2 \%$ (do sexo masculino) e 1\% (do sexo feminino) dos pardos e 3\% (do sexo masculino) e 1\% (do sexo feminino) dos pretos (Instituto Brasileiro de Geografia e Estatística, 2000). Percebe-se, nestes resultados, não somente um número muito pequeno 
daqueles que se autodeclaram pretos, mas uma pequena participação da população residente em Sergipe que trabalha na indústria de transformação sergipana.

Quadro 1: População ocupada com carteira assinada, segundo participação dos grupos por raça ou cor e sexo, distribuída na indústria de transformação sergipana em 2007, 2008, 2013 e 2014

\begin{tabular}{|c|c|c|c|c|c|c|c|}
\hline \multirow[t]{2}{*}{ Raça/Cor } & \multicolumn{2}{|c|}{$2007 / 2008$} & \multirow[t]{2}{*}{ Subtotal } & \multirow[t]{2}{*}{ Raça/Cor } & \multicolumn{2}{|c|}{$2013 / 2014$} & \multirow[t]{2}{*}{ Subtotal } \\
\hline & M & F & & & M & F & \\
\hline \multirow[t]{4}{*}{ Branca } & 12324 & 4714 & 17038 & \multirow[t]{4}{*}{ Branca } & 15696 & 6784 & 22480 \\
\hline & $71 \%$ & $29 \%$ & $27 \%$ & & $70 \%$ & $30 \%$ & $26 \%$ \\
\hline & $27 \%$ & $28 \%$ & & & $26 \%$ & $28 \%$ & \\
\hline & $20 \%$ & $8 \%$ & & & $18 \%$ & $8 \%$ & \\
\hline \multirow[t]{4}{*}{ Parda } & 30414 & 11377 & 41791 & \multirow[t]{4}{*}{ Parda } & 41060 & 16194 & 57254 \\
\hline & $73 \%$ & $27 \%$ & $66 \%$ & & $72 \%$ & $28 \%$ & $66 \%$ \\
\hline & $65 \%$ & $67 \%$ & & & $65 \%$ & $66 \%$ & \\
\hline & $48 \%$ & $18 \%$ & & & $47 \%$ & $19 \%$ & \\
\hline \multirow[t]{4}{*}{ Preta } & 3503 & 819 & 4322 & \multirow[t]{4}{*}{ Preta } & 5344 & 1406 & 6750 \\
\hline & $81 \%$ & $19 \%$ & $7 \%$ & & $79 \%$ & $21 \%$ & $8 \%$ \\
\hline & $8 \%$ & $5 \%$ & & & $9 \%$ & $6 \%$ & \\
\hline & $6 \%$ & $1 \%$ & & & $6 \%$ & $2 \%$ & \\
\hline \multirow[b]{2}{*}{ Total } & 46241 & 16910 & \multirow[t]{2}{*}{63151} & \multirow[b]{2}{*}{ Total } & 62100 & 24384 & 86484 \\
\hline & $73 \%$ & $27 \%$ & & & $72 \%$ & $28 \%$ & \\
\hline
\end{tabular}

Fonte: Ministério do Trabalho e Emprego/CGET: Microdados RAIS.

A população residente sergipana branca, parda e preta é constituída, segundo o Censo de 2010, respectivamente por 583.428, 1.269 .565 e 184.054, correlacionando-a com os dados RAIS de 2013 e 2014, esta população corresponde a 3\% (do sexo masculino) e 1\% (do sexo feminino) dos vínculos formais de trabalhadores brancos, 3\% (do sexo masculino) e 1\% (do sexo feminino) dos pardos e 3\% (do sexo masculino) e 1\% (do sexo feminino) dos pretos. Embora tenha sido identificado um aumento da população residente sergipana preta, entre os Censos de 2000 e 2010, sua participação na indústria de transformação sergipana permaneceu estagnada.

A mão de obra ocupada com carteira assinada do sexo feminino de cor preta, entre os Censos de 2000 e 2010, apresenta uma evolução na sua taxa de participação no mercado de trabalho sergipano como um todo e o mesmo grupo apresenta uma pequena evolução na sua participação na indústria de transformação sergipana, nos anos de 2007, 2008, 2013 e 2014. Ao confrontar tais dados, percebe-se que há uma pequena participação das mulheres pretas com vínculos formais na indústria de transformação. $\mathrm{O}$ mesmo pode ser observado em relação aos vínculos formais dos homens pretos.

Quanto às diferenças salariais entre homens e mulheres, na indústria de transformação sergipana, nota-se, na Figura 5, que tanto os trabalhadores do sexo masculino quanto do feminino da cor branca, parda e preta tiveram, no período analisado, um aumento na sua remuneração. Enquanto a remuneração dos vínculos formais dos homens brancos em relação às mulheres pretas, conforme observado na Figura 6, mantiveram-se os mesmos com uma diferença de 2,1 pontos dos primeiros em relação aos segundos. Durante o período, os vínculos 
formais dos homens pardos e pretos apresentaram remunerações médias acima dos vínculos formais das mulheres pardas e pretas.

Se tais diferenças salariais entre homem branco versus mulher branca e mulher parda versus mulher preta aumentaram, esse fato não apenas reflete as desigualdades de gênero e de raça existentes no setor industrial sergipano, mas também a confirmação de que os homens brancos estão no topo da pirâmide e as mulheres pretas na base. De modo que as trabalhadoras pretas detêm as remunerações substancialmente mais baixas ( $\mathrm{R} \$ 766,96)$ do que os demais grupos, e os trabalhadores brancos possuem uma remuneração média superior ( $\mathrm{R} \$ 1.640,86$ ) aos pardos $(\mathrm{R} \$ 1.168,85)$ e pretos $(\mathrm{R} \$ 1.091,96)$, seguidos pelas trabalhadoras brancas $(\mathrm{R} \$$ $993,24)$ e pardas $(\mathrm{R} \$ 828,48)$.

Segundo dados da PNAD, em 2002 (Pinto, 2006), os homens brancos apresentavam um rendimento médio de $\mathrm{R} \$ 1.102,50$ e as mulheres brancas $\mathrm{R} \$ 686,70$; os homens negros, em média, $\mathrm{R} \$ 521,10$ e as mulheres negras $\mathrm{R} \$ 342,50$. Os homens brancos lideram com relação a todos os outros, as mulheres brancas ganham mais do que os homens e mulheres negros, mas é, sobretudo, contra as negras que a disparidade pesa mais: elas ganham praticamente a metade do rendimento das brancas e a quarta parte do rendimento dos brancos (Pinto, 2006).

Resultado semelhante foi encontrado em 2006, quando o rendimento real médio mensal do trabalho principal dos homens brancos, em todo o país, equivalia a $\mathrm{R} \$ 1.164,00$. Este valor, no mesmo ano, era 56,3\% superior à mesma remuneração obtida pelas mulheres brancas $(\mathrm{R} \$ 744,11), 98,5 \%$ superior à auferida pelos homens pretos e pardos $(\mathrm{R} \$ 586,26)$ e $200 \%$ à recebida pelas mulheres pretas e pardas ( $\mathrm{R} \$ 388,18)$ (Paixão \& Gomes, 2008).

Quando se trata dos dados RAIS, no mercado de trabalho formal, em relação à remuneração média, os grupos sociais se posicionam hierarquicamente da seguinte forma: os homens brancos no topo e as mulheres negras na base da pirâmide. Quando se trata de dados da PNAD, do mercado de trabalho formal e informal, os homens brancos e as mulheres pretas permanecem respectivamente no topo e na base da pirâmide, com uma pequena alteração: as mulheres brancas apresentam remunerações maiores do que os homens pardos e pretos.

Diante de tais resultados, o cruzamento entre categorias como sexo e raça ou cor parece surtir um efeito maior sobre os vínculos formais constituídos pelas mulheres pretas do setor industrial sergipano, cuja articulação entre o racismo e o sexismo contribui para que este grupo sofra um grau maior de discriminação em relação aos demais grupos no mercado de trabalho. Em relação à remuneração média, observa-se que os grupos sociais estão distribuídos hierarquicamente da seguinte forma: homens brancos no topo e mulheres negras na base, ou seja, há uma tendência maior à discriminação de gênero no setor industrial sergipano.

Embora, no caso da indústria de transformação sergipana, a remuneração média de mulheres pardas e pretas esteja muito próxima uma da outra, é aconselhável não considerá-las apenas como uma categoria, isso porque reconhecer mulheres pardas e pretas como negras, consiste em desconsiderar o efeito da escravidão, da colonização e do racismo sobre as diferenças sociais construídas historicamente e responsáveis pelas desigualdades de raça e gênero presentes no mercado de trabalho (Biroli \& Miguel, 2015).

Conclui-se, então, que, em função das categorias raça ou cor, as mulheres pretas estão sujeitas à dupla discriminação, cujas desigualdades de raça e gênero são vistas como determinantes da discriminação laboral. Dessa forma, ainda que as mulheres negras elevem o 
seu nível de escolaridade, continuarão a ocupar os mais baixos níveis sociais, por enfrentarem fortes barreiras para converterem suas melhores qualificações em maiores vantagens no mercado de trabalho (Borges, 2013; Lima, Rios, \& França, 2013).

A discriminação consiste no agir baseado em categorias "naturais" e sociais sem que haja relação com as capacidades e os méritos individuais, ou seja, o ato de separar tanto pode privilegiar um grupo ou pessoa quanto prejudicá-los, exigindo uma compreensão acerca do tipo de diferenciação que produz e a espécie de informação que sustenta e gera exclusão (Ministério da Educação, 2008). Os mecanismos de discriminação presentes na indústria de transformação sergipana são entendidos a partir dessas diferenciações na taxa de participação, no capital humano, na ocupação profissional e na remuneração média que existem entre vínculos formais dos trabalhadores brancos, pardos e pretos.

Figura 5: População ocupada com carteira assinada, segundo participação dos grupos por raça ou cor e sexo, distribuída por remuneração média na indústria de transformação sergipana em 2007, 2008, 2013 e 2014

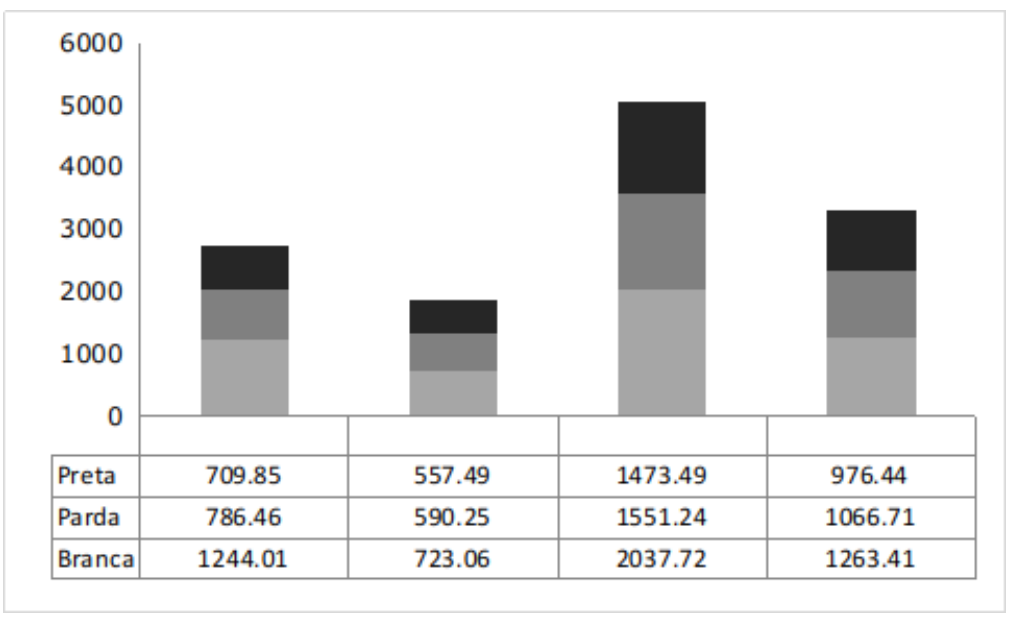

Fonte: Elaboração própria.

A discriminação racial é, então, toda distinção, restrição ou preferência baseada na raça ou cor, descendência ou origem nacional ou étnica que tenha por objetivo restringir o reconhecimento, gozo ou exercício em um mesmo plano (em igualdade de condições) de direitos humanos e liberdades fundamentais nos campos políticos, econômico, cultural ou qualquer outro da vida pública (Organização das Nações Unidas, 1998). As desigualdades de gênero e raça são comprovadas por dados RAIS e é nítido o fato de que há discriminação tanto de gênero quanto de raça na indústria de transformação sergipana.

Julga-se pertinente destacar que, embora desde 1998 o Instituto Ethos tenha publicado diversos documentos de combate à discriminação no mercado de trabalho e de promoção da diversidade organizacional, nem todas as empresas distribuídas pelos estados do Brasil se associaram ao Instituto. $\mathrm{O}$ efeito da norma de responsabilidade social sobre o posicionamento de mulheres negras, em determinados setores da economia, não apenas é nulo como também dificulta a correlação entre norma social e comportamento organizacional, ou seja, é difícil identificar até que ponto os racistas aversivos, influenciados pela norma de responsabilidade social empresarial, evitam expor explicitamente suas atitudes preconceituosas. 
Figura 6: População ocupada por carteira assinada, segundo participação dos grupos por raça ou cor e sexo, distribuída por remuneração média na indústria de transformação sergipana em 2007, 2008, 2013 e 2014

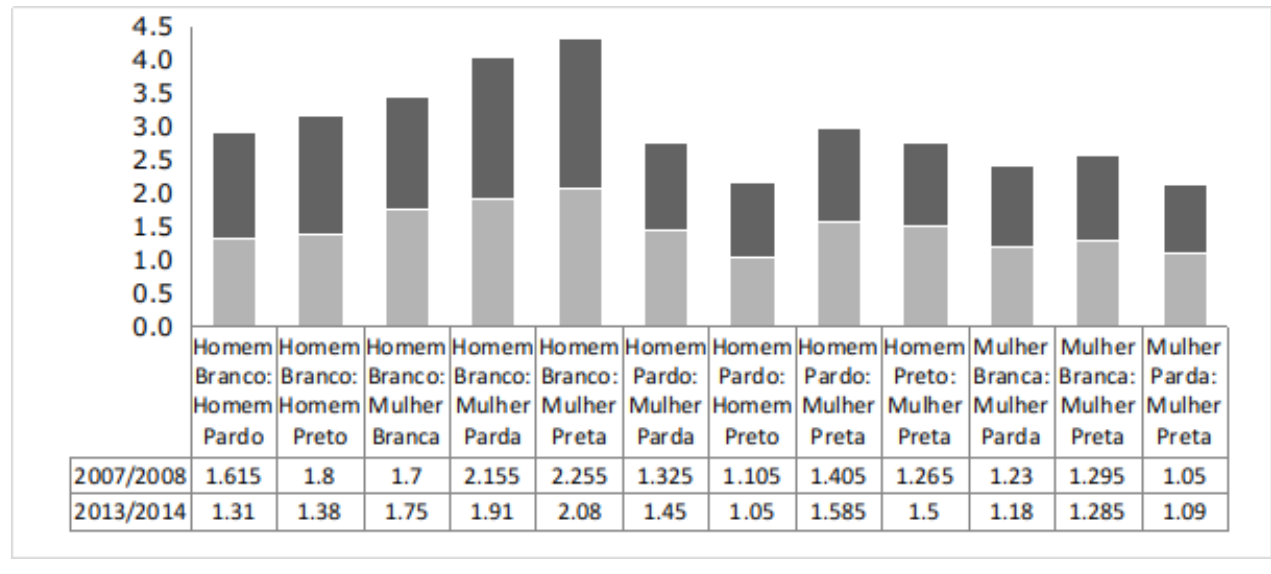

Fonte: Elaboração própria.

\section{Considerações finais}

Uma das limitações deste estudo consiste no método de classificação da categoria raça ou cor, utilizado pela RAIS, no seu formulário. Se, nos censos demográficos, o critério de classificação da raça ou cor do emprego é autoclassificatório, corre-se o risco de alguém de aparência branca se declarar negro ou vice-versa. Quando se trata de registros administrativos, como a RAIS, a situação se complica porque o método utilizado para classificação da raça ou cor é o heteroclassificatório, no qual é o empregador e não o empregado que declara a raça ou cor do empregado (Paixão, Rosseto, \& Monçores, 2013).

Comparando os Microdados RAIS com os produzidos pela Pesquisa Nacional por Amostra de Domicílios (PNAD), quanto ao quesito raça ou cor, adotado nos seus formulários, constatou-se que o maior problema do critério heteroclassificatório adotado pela RAIS é o de apresentar uma maior vulnerabilidade em relação aos padrões étnico-raciais ainda hegemônicos no país, o que a levaria a um perfil de distribuição relativamente mais branco do que os Microdados PNAD produzido pelo Instituto Brasileiro de Geografia e Estatística (IBGE) (Paixão, Rosseto, \& Monçores, 2013).

As implicações dos resultados apresentados pelos dados RAIS podem estar em consonância com o pertencimento racial, ou seja, com a dificuldade em definir-se negro no Brasil — principalmente quando se discute políticas de ações afirmativas — não somente em razão biológica de que muitos brasileiros aparentemente considerados brancos trazem traços marcadores genéticos africanos, mas pelo desejo do embranquecimento. Por conta desta miscigenação, o negro no Brasil é diferente do negro nos Estados Unidos da América, onde não existem as categorias pardo, mulato ou mestiço, e qualquer descendente de negro pode simplesmente se apresentar como negro (Munanga, 2004, p. 52). Por outro lado, a cor, como uma construção ideológica, adquiriu a função de marcar socialmente a posição dos indivíduos ou grupos dentro de uma determinada estrutura social. 
Nesse sentido, tanto este estudo confirmou a dupla discriminação sofrida pelas mulheres negras na indústria de transformação, como diversos outros estudos, sobre a discriminação interseccional no mercado de trabalho, constataram que o Brasil ainda é extremamente colonial e que sua história é constituída não apenas de desigualdades sociais e econômicas, mas também de injustiça social. O Brasil é um país onde se herda do colonizador a noção de que a raça e o sexo compõem uma situação natural de inferioridade que justifica o racismo e a discriminação indireta.

\section{Referências}

Bento, M. A. S. (1995). A mulher negra no mercado de trabalho. Estudos Feministas, 3 (2), 479-488. Recuperado de: https://periodicos.ufsc.br/index.php/ref/article/view/16466

Biroli, F. \& Miguel, L. F. (2015). Gênero, raça, classe: opressões cruzadas e convergências na reprodução das desigualdades. Mediações - Revista de Ciências Sociais, 20 (2), 27-55. Recuperado de: http://www.uel.br/revistas/uel/index.php/mediacoes/article/view/24124

Borges, R. S. (2013). Pensando a transversalidade de gênero e raça. In G. Venturi \& T. Godinho (Eds.). Mulheres brasileiras e gênero nos espaços público e privado (pp. 63-89). São Paulo: Perseu Abramo.

Carneiro, P., Heckman, J. J., \& Masterov, D. V. (2003). Understanding the sources of ethnic and racial wage gaps and their implications for policy. In ABF conference Rights and Realities: Legal and Social Scientific Approaches to Employment Discrimination (p. 58). Standford, CA. Recuperado de http://www.ucl.ac.uk/ uctppca/disc.pdf

Carone, I. (2009). Igualdade versus diferença: um tema do século. Programa de apoio Pedagógico na Relação Educação e Tecnologia da Faculdade de Educação da Unicamp. Recuperado de http://www.lite.fe.unicamp.br/ papet/2003/ep403/igualdade_versus_diferenca.htm

Carvalhaes, F. \& Ribeiro, C. A. C. (2019). Estratificação horizontal da educação superior no Brasil: Desigualdades de classe, gênero e raça em um contexto de expansão educacional. Tempo Social, 31 (1), 195-233. Recuperado de: http://www.scielo.br/scielo.php?script=sci_abstract\&pid=S0103-20702019000100195 $\& \operatorname{lng}=\mathrm{pt} \& \mathrm{nrm}=\mathrm{iso}$

Casaca, S. F. (2009). Revisitando as teorias sobre a divisão sexual do trabalho. SOCIUS Working Papers, 4, 1-61. Recuperado de https://www.repository.utl.pt/bitstream/10400.5/1116/1/WP_4_2009.ultima.versao.pdf

Cruz, M S. (2010). Atitudes, expectativas e discriminação no mercado de trabalho brasileiro. Tese de Doutorado, Departamento de Economia Aplicada, Universidade Federal do Ceará, Fortaleza. Recuperado de http://www.repositorio.ufc.br/handle/riufc/683

Custódio, A. L. M. \& Moya, R. (2007). Indicadores Ethos de Responsabilidade Social Empresarial 2007. Recuperado de https://www3.ethos.org.br/wp-content/uploads/2013/07/IndicadoresEthos_2013_PORT.pdf

Domingues, P. (2008). Decifrando os segredos internos: a transição do trabalho escravo para o livre no Brasil. Iberoamericana, 8 (31), 197-205. Recuperado de: https://www.jstor.org/stable/41676656

Dovidio, J. F. \& Gaertner, S. L. (2004). Aversive Racism. Advances in experimental Social Psychology, 36, 1-51. Recuperado de http://www.psych.purdue.edu/ willia55/392F-'06/Dovidio\&Gaertner.pdf

Estatísticas de Gênero 1 - Escolaridade das mulheres aumenta em relação à dos homens (2014, 14 de novembro). Instituto Patrícia Galvão. Recuperado de http://agenciapatriciagalvao.org.br/trabalho_/estatisticas-degenero-1-escolaridade-das-mulheres-aumenta-em-relacao-dos-homens/

Federação da Indústria do Estado de Sergipe. (2012). Cadastro Industrial de Sergipe. Recuperado de http://www.fies.org.br/leitura/29/cadastroindustrial.html

Instituto Brasileiro de Geografia e Estatística. (2000). Universo - Características da população de dos domicílios. Recuperado de http://www2.sidra.ibge.gov.br/bda/tabela/protabl.asp?c $=210 \& z=\mathrm{cd} \& o=27 \& \mathrm{i}=\mathrm{P}$ 
Instituto Brasileiro de Geografia e Estatística. (2007). Classificação nacional de atividades econômicas - CNAE. Recuperado de http://www.ibge.gov.br/home/estatistica/economia/classificacoes/cnae2.0/cnae2.0.pdf

Instituto Brasileiro de Geografia e Estatística. (2010). Universo - Características da população de dos domicílios. Recuperado de http://www2.sidra.ibge.gov.br/bda/tabela/protabl.asp?c $=3177 \& z=\mathrm{cd} \& \mathrm{o}=7 \& \mathrm{i}=\mathrm{P}$

Instituto Brasileiro de Geografia e Estatística. (2014). Estatística de Gênero: Uma análise do censo demográfico de 2010 (Estudos e Pesquisas Informação Demográfica e Socioeconômica número 33). Recuperado de http://biblioteca.ibge.gov.br/index.php/biblioteca-catalogo?view= detalhes\&id=288941

Instituto Ethos. (2010). Perfil social, racial e de gênero das 500 maiores empresas do Brasil. Recuperado de https://www3.ethos.org.br/cedoc/perfil-social-racial-e-de-genero-das-500-maiores-empresas-do-brasil-esuas-acoes-afirmativas-pesquisa-2010/\#.W2KEJUxFzIU

Kometani, P. (2017, 15 de março). Mulheres ganham menos do que os homens em todos os cargos, diz pesquisa. G1 Globo. Recuperado de https://g1.globo.com/economia/concursos-e-emprego/noticia/mulheres-ganhammenos-do-que-os-homens-em-todos-os-cargos-diz-pesquisa.ghtml

Lima, M., Rios, F., \& França, D. (2013). Articulando gênero e raça: a participação das mulheres negras no mercado de trabalho. In M. M. Marcondes et al. (Orgs.). Dossiê mulheres negras: retrato das condições de vida das mulheres negras no Brasil (pp. 53-80). Recuperado de http://www.ipea.gov.br/igualdaderacial/index.p hp?option=com_content\&view $=$ article $\&$ id $=731$

Lima, M. E. O. \& Vala, J. (2004). As novas formas de expressão do preconceito e do racismo. Estudos de Psicologia, 9 (3), 401-411. Recuperado de: http://www.scielo.br/scielo.php?script=sci_arttext\&pid=S1413. $294 \times 2004000300002$

Martins, E., Santos, A. O., \& Colosso, M. (2013). Relações étnico-raciais e psicologia: publicações em periódicos da SciElO e Lilacs. Psicologia: Teoria e Prática, 15 (3), 118-133. Recuperado de: http://pepsic.bvsalud.org/scielo.php?script=sci_arttext\&pid=S1516-36872013000300009

Ministério da Educação. (n. d.). Estereótipos, preconceito e discriminação. Recuperado de https:/grupos.moodle.ufsc.br/ pluginfile.php/1706/mod_resource/content/0/modulo4/mod4_unidade2_texto5.pdf

Ministério do Trabalho e Emprego. (2014). Dados Aleatórios - Microdados da RAIS. Recuperado de http://www.dadosaleatorios.com.br/2014/05/microdados-da-rais.html

Mummendey, A. \& Wenzel, M. (1999). Social discrimination and tolerance in intergroup relations: Reactions to intergroup difference. Personality and Social Psychology Review, 3 (2), 158-74. Recuperado de: https://www.ncbi.nlm.nih.gov/pubmed/15647144

Munanga, K. (2004). A difícil tarefa de definir quem é negro no Brasil. Estudos Avançados, 18 (50), 51-56. Recuperado de: http://www.scielo.br/scielo.php?script=sci_arttext\&pid=S0103-40142004000100005

Negri, J. A., Castro, P. F. de, Souza, N. R. de, \& Arbache, J. S. (2001). Mercado de trabalho formal: Comparação entre os Microdados da RAIS e da PNAD. Instituto de Pesquisa Econômica Aplicada. Recuperado de http://repositorio.ipea.gov.br/handle/11058/2155

Organização das Nações Unidas. (1998). Convenção da ONU de 21 de dezembro de 1965: Sobre a eliminação de todas as formas de discriminação racial. Recuperado de http://unesdoc.unesco.org/images/0013/001393/ 139390por.pdf

Pager, D. (2006). Medir a discriminação. Tempo Social, 18 (2), 65-88. Recuperado de http://www.revistas.usp.br/ts/article/view/12515/14292

Paixão, M. \& Gomes, F. (2008, setembro). Histórias das diferenças e das desigualdades revisitadas: notas, sobre gênero, escravidão, raça e pós-emancipação. Revista de Estudos Feministas, 16 (3), 949-964. Recuperado de: http://www.scielo.br/scielo.php?pid=S0104-026X2008000300014\&script=sci_abstract\&tlng=pt

Paixão, M., Rosseto, I., \& Monçores, E. (2013). Investigação sobre a qualidade da variável cor ou raça na RAIS através de um estudo comparativo com a PNAD e o IBGE. In 36ํㅡㄹ contro Anual da ANPOCS (pp. 1-28). Águas de Lindóia, SP. Recuperado de http://www.anpocs.org/portal/index.phpoption=com_docman\&task $=$ doc_view\&gid $=8349 \&$ Itemid $=76$ 
Pinto, G. (2006). Situação das mulheres negras no mercado de trabalho: uma análise dos indicadores sociais. Recuperado de http://files.ufgd.edu.br/arquivos/arquivos/78/NEAB/Giselle\%20Pinto.PDF

Quillian, L. (2006). New approaches to understanding racial prejudice and discrimination. Annual Review of Sociology, 32, 299-328. doi: 10.1146/annurev.soc.32.061604.123132

Saboia, J. L. M. \& Tolipan, R. M. L. (1985, agosto). A relação anual de informações sociais (RAIS) e o mercado formal de trabalho: uma nota. Pesquisa Plano Econômico 15 (2), 447-456. Recuperado de: http://repositorio.ipea.gov.br/handle/11058/6161

Sacco, A. M., Couto, M. C. P. P., \& Koller, S. H. (2016). Revisão Sistemática de estudos de psicologia brasileira sobre preconceito racial. Temas psicologia, 24 (1), 233-250. Recuperado de: http://pepsic.bvsalud.org/scielo.php? script $=$ sci_arttext\&pid $=$ S1413-389X2016000100012

Servo, L. M. S., Furtado, P., Amorim, B. M. F., Ribeiro, E. P., \& Souza, A. L. (2006). Base de dados: apresentação e opções metodológicas. In C. Henrique Courseuil \& L. M. S. Servo (Orgs.). Criação, destruição e realocação de empregos no Brasil (pp. 09-103). Brasília: IPEA. Recuperado de: http://www.ipea.gov.br/portal/index.php? option $=$ com_content\&view $=$ article $\& i d=5534$

Silva, V. P., Lima, M. E. O., \& Silva, P. (2017). Teoria do Racismo Aversivo. In A discriminação da mulher negra no setor industrial sergipano entre 2007 e 2014: Uma análise dos impactos da norma de responsabilidade social empresarial. Dissertação de Mestrado em Psicologia Social, Programa de Pós-Graduação em Psicologia, Universidade Federal de Sergipe, Aracaju.

Soares, S. D. (2000). O perfil da discriminação no mercado de trabalho: homens negros, mulheres brancas e mulheres negras. Brasília: IPEA. Recuperado dehttp://www.ipea.gov.br/agencia/images/stories/PDFs/TDs/td_0769.pdf

Souza, P. F. L., Salvato, M. A., \& França, J. M. (2013). Ser mulher e negro no Brasil ainda leva a menores salários? Uma análise de discriminação para Brasil e regiões: 2001 e 2011. In XLI Encontro Nacional de Economia (p. 19). Foz do Iguaçu, PR. Recuperado de https://www.anpec.org.br/encontro/2013/files_I/i13fdf7ed2c0ef980eed5174b846032f924.pdf

Telles, E. E. (2004). O significado da raça na sociedade brasileira. Recuperado de https://professorsauloalmeida. files.wordpress.com/2014/07/livro-o-significado-da-raca-na-sociedadebrasileira2.pdf

Vasconcellos, M. A. \& Silva, R. H. (2013). Reflexões teóricometodológicas sobre a análise documental em processos judiciais trabalhistas. Revista da ABET, 12 (2), 115-132. Recuperado de: https://periodicos.ufpb.br/ojs/ index.php/abet/article/view/20201

\section{Endereço para correspondência:}

valdenice.portela3@gmail.com,marcuseolima@gmail.com, dasilvapaty@yahoo.com.br 